\title{
A community reinforcement and family training approach was effective in engaging unmotivated problem drinkers in treatment
}

Miller WR, Meyers RJ, Tonigan JS. Engaging the unmotivated in treatment for alcohol problems: a comparison of three
strategies for intervention through family members. J Consult Clin Psychol 1999 Oct;67:688-97.

QUESTION: In patients with alcohol problems, are interventions through family

members effective in engaging the unmotivated in treatment?

\section{Design}

Randomised \{allocation concealed $*\}$, blinded (outcome assessors)*, controlled trial with 1 year of follow up.

\section{Setting}

Center on Alcoholism, Substance Abuse, and Addictions, Albuquerque, New Mexico, USA.

\section{Patients}

130 concerned significant others (CSOs) (mean age 47 y, $91 \%$ women) living with a problem drinker (behaviour consistent with DSM-III-R criteria and who had refused to seek treatment). The CSO was either a close relative, spouse or unmarried intimate partner and in contact with the drinker for at least $40 \%$ of the previous 90 days. Exclusion criteria included the $\mathrm{CSO}$ had a substance use disorder, psychosis was present in the CSO or drinker, and the drinker had an illicit drug problem or had engaged in domestic violence. $94 \%$ completed follow up.

\section{Intervention}

$45 \mathrm{CSO}$ s were allocated to Al-Anon facilitation (designed to encourage involvement in the 12 step programme), 40 were allocated to the Johnson Institute intervention (designed to prepare for a confrontational family meeting), and 45 were allocated to a community reinforcement and family training (CRAFT) approach teaching behaviour change skills to use at home. All treatments were manual guided with 12 hours of contact.

\section{Main outcome measures}

Number of problem drinkers engaged in treatment at follow up, change in CSO functioning, and relationship quality.

\section{Main results}

Analysis was by intention to treat. The CRAFT approach was more effective in engaging initially unmotivated problem drinkers in treatment compared with the Al-Anon and Johnson interventions (table). No difference existed between the Al-Anon and Johnson interventions (table). All 3 approaches were associated with similar improvement in CSO functioning and relationship quality.

\section{Conclusion}

A community reinforcement and family training approach was more effective than Al-Anon and the Johnson Institute intervention in engaging initially unmotivated problem drinkers in treatment.

*See glossary.

$\dagger$ Information provided by author.

\section{COMMENTARY}

Clinicians have long recognised that patient motivation is absolutely critical to success in treating alcohol and drug abuse. The barriers to successful treatment are numerous and include codependent family members as well as the substance abuser's denial of a problem and/or willingness to seek treatment. The study by Miller $e t a l$ addresses 2 fundamental relationships: (1) between the problem drinker's own degree of motivation to engage in treatment and the potential role of the drinker's social support network in initiating and sustaining treatment; and (2) between the emotional status of CSOs and the ability of the CSO to facilitate treatment initiation and engagement.

The results of this study show that training CSOs in behavioural change techniques was as effective in improving CSO functioning and relationship quality as 2 other widely used cognitive behavioural interventions, Al-Anon and the Johnson Institute confrontation based intervention. The CRAFT approach, however, was substantively more effective in engaging initially unmotivated problem drinkers in treatment. Thus, of the 3 interventions examined, only the CRAFT approach appears to meet the needs of the problem drinker and the CSO at the same time.

Not all problem drinkers will benefit from this approach, especially if they are already predisposed to treatment. In these instances, Al-Anon may be a more cost-effective approach to improving CSO functioning and quality of life. Similarly, the fact that only $30 \%$ of patients elected to use the Johnson Institute intervention after having undergone training in the confrontational approach suggests that this intervention may not be a cost-effective strategy in general (especially if it is unlikely that it will be employed), or effective with a relatively small segment of the population of problem drinkers and their CSOs. This study shows that functional, healthy social networks offer enormous potential in engaging unmotivated problem drinkers in treatment. These networks are of little value however unless they possess the skills necessary to facilitate engagement.

Lawrence A Palinkas, $\mathrm{PhD}$

University of California, San Diego La Jolla, California, USA

A community reinforcement and family training (CRAFT) approach v Al-Anon (Al-A) facilitation and the Johnson Institute (JI) intervention in concerned significant others living with a problem drinker $\$$

\begin{tabular}{lllll}
$\begin{array}{c}\text { Outcomes at } 12 \\
\text { months }\end{array}$ & Comparison & Rates & RBI (95\% CI) & NNT (CI) \\
$\begin{array}{c}\text { Problem drinker } \\
\text { engaged in } \\
\text { treatment }\end{array}$ & CRAFT $v$ Al-A & $67 \% v 20 \%$ & $233 \%(87$ to 530$)$ & $3(2$ to 4$)$ \\
\cline { 2 - 5 } & CRAFT $v \mathrm{JI}$ & $67 \% v 35 \%$ & $90 \%(22$ to 212$)$ & $4(2$ to 10$)$ \\
\cline { 2 - 5 } & $\mathrm{Al}-\mathrm{A} v \mathrm{JI}$ & $35 \% v 20 \%$ & $75 \%(-13$ to 259$)$ & Not significant \\
\hline
\end{tabular}

$\neq$ Abbreviations defined in glossary; RBI, NNT, and $\mathrm{Cl}$ calculated from data in article. 